\title{
EDITOR'S PERSPECTIVE
}

1. The technique for endoscopic pituitary tumor removal. Michael D. Cusimano and Ronald S. Fenton

2. Endoscopic endonasal transsphenoidal surgery: experience with 50 patients. Hae-Dong Jho and Ricardo L. Carrau

3. Endoscopic transsphenoidal resection of a large chordoma in the posterior fossa. Case report. Hae-Dong Jho, Ricardo L. Carrau, Mark L. McLaughlin, and Salvador C. Somaza

These three articles deal with a topic that is clearly a "hot" issue, namely endoscopic techniques for transsphenoidal surgery. These techniques have been advocated at our neurosurgical meetings and are catching on around this country and in Canada. The technical aspects of endoscopic pituitary surgery are still evolving, and this reviewer has some limited experience that would indicate both the promise of the technique and some of the pitfalls of current application. From my perspective the major disadvantages of the endoscopic technique are limited space when the surgeon is faced with complications, and the fact that with most currently available endoscopes, one loses three-dimensional vision. The advantages of a "minimally invasive," relatively atraumatic technique are clear. I remember how "minimally invasive" the transsphenoidal operation appeared compared to craniotomy back in the late 1960s and early 1970s when transsphenoidal surgery was reintroduced for management of pituitary lesions.

Clearly some patients will benefit from endoscopic transnasal pituitary surgery; however, it will be some time before experienced pituitary surgeons will be able to accumulate outcome results that indicate whether the basic disease is actually treated more effectively using these "new" techniques. Eventually, the use of endoscopic methodology should enhance the versatility of transnasal transsphenoidal approaches to pituitary lesions. Hopefully this will allow pituitary surgery to be even more effective in dealing with a number of endocrine and neoplastic disorders. 